\title{
Análise da viabilidade econômico-financeira de sistemas de cria em gado de corte: estudo de múltiplos casos
}

[Economic-financial analysis of cow-calf systems: multiple case studies]

\author{
F.Z. Garcia ${ }^{1}$, C.A.B. Carvalho ${ }^{1}$, A.A.C. Peres $^{2}$, P. Malafaia ${ }^{1}$, P.M. Souza ${ }^{3}$ \\ ${ }^{1}$ Universidade Federal Rural do Rio de Janeiro - IZ/DNAP - Seropédica, RJ \\ ${ }^{2}$ Universidade Federal Fluminense - EEIMVR/VEA - Volta Redonda, RJ \\ ${ }^{3}$ Universidade Estadual do Norte Fluminense - CCTA/LEAG - Campos de Goytacazes, RJ
}

\section{RESUMO}

Muitas fazendas, situadas em bacias leiteiras, estão migrando da atividade leiteira para a pecuária de corte e tal migração vem sendo feita de forma muitas vezes não criteriosa ou sem assistência técnica. Neste estudo, objetivou-se avaliar a viabilidade econômico-financeira e o risco econômico de diferentes sistemas de cria de gado de corte, explorados em regiões de bacia leiteira. O trabalho consistiu em um estudo de múltiplos casos que tiveram como critério de escolha três sistemas que desenvolvessem atividade de cria. O horizonte de informações econômicas dos sistemas foi de 36 meses e os sistemas de criação foram caracterizados por meio de levantamento de dados realizados em visitas periódicas, utilizando-se questionários previamente elaborados. Foram estimados o valor presente líquido e a taxa interna de retorno do investimento, e realizaram-se as análises de sensibilidade e o risco de cada sistema de criação. Os três sistemas de cria foram viáveis financeiramente por terem VPL positivo a uma taxa de desconto de $6,0 \%$ a.a. O retorno da atividade mostrou-se mais sensível aos investimentos realizados na compra de terra e nas matrizes. Os riscos desses sistemas, apesar da possibilidade de mudanças no mercado, foram considerados baixos, tornando-os opções de investimentos atrativas, quando comparados aos rendimentos obtidos com a caderneta de poupança.

Palavras-chave: avaliação econômica, bezerros, gado de corte

\begin{abstract}
Many farms located in milk-producing regions in Brazil have turned from dairy to beef production systems. These business migrations have been done with no particular care or any use of technical assistance. In this study, we aimed to evaluate the economics aspects, such as viability and risk assessment of different cow-calf systems established in those regions. The work consisted of a multiple case study using three farms. The economic horizon lasted 36 months, with data collection obtained in periodic visits, using a pre-designed survey. Net present value (NPV) and internal rate of return (IRR) on investment were estimated. Further analysis of sensitivity was made for these indicators. -All cow-calf systems were economically viable with positive NPV, with a discount rate of $6.0 \%$ per year. The economic viability of the cow-calf systems was more sensitive to investments in land and animals ( sires and cows). The assessment of risks in these cow-calf systems showed them to be low, despite the possibility of changes in the market. The cow-calf systems, when submitted to technical assistance, may be an attractive option of investment compared to investing in saving account.
\end{abstract}

Keywords: cow-calf system, economic analysis, net present value

\section{INTRODUÇÃO}

Entre as etapas de produção na pecuária de corte (cria, recria e terminação), a cria pode ser

Recebido em 2 de outubro de 2016

Aceito em 10 de outubro de 2016

E-mail: felipegarcia@zootecnista.com.br considerada a principal fase, visto que fornece o bezerro, que é o insumo principal para a produção de carne bovina. Quanto à sua viabilidade financeira, o sistema de cria pode ser considerado de baixa rentabilidade quando 
comparado com o sistema de recria ou terminação (Barcellos, 2011). Essa assertiva se deve ao longo período que envolve a estação de monta, a gestação e os sete a oito meses desde o nascimento até a venda do bezerro desmamado. Nesse sentido, Lazzarini Neto (2000) relatou que a menor rentabilidade da atividade de cria devese ao grande capital imobilizado pelo criador em matrizes, touros, novilhas e na própria terra.

Contudo, segundo Barcellos (2011), o bezerro vem se valorizando nos últimos anos devido à mudança de hábito dos consumidores, que passaram a exigir carne com qualidade, pressionando os frigoríficos a buscarem matériaprima que a demanda exige. Desse modo, os recriadores e os terminadores sofreram pressão econômica e social para obtenção de maior eficiência, necessitando de reposição com qualidade, a qual somente pode advir de sistemas de cria que tenham como base o tripé fundamental: sanidade, nutrição e genética superior. A menor oferta de bezerros de reposição para recria/engorda, gerada pelo grande abate de fêmeas nos últimos anos, foi também apontada pelo autor como causa da elevação do preço do bezerro desmamado e, consequentemente, do aumento na rentabilidade da atividade.

No entanto, períodos de bons preços e de boa rentabilidade também possuem riscos, os quais ficam encobertos pelo estímulo a investimentos que serão pagos, geralmente ad annum, quando o produto gerado poderá ser comercializado por menor valor, devido a fatores extrínsecos à fazenda. Dessa forma, investir e aumentar a eficiência são fatores intrínsecos importantes, mas devem ser acompanhados por um planejamento financeiro e por uma gestão de riscos para servirem como critérios na tomada de decisão. A avaliação técnica e econômicofinanceira de sistemas de produção pode proporcionar aos pecuaristas informações que indiquem o aumento da produção dos animais e da produtividade por área, com redução dos custos de produção e aumento da rentabilidade (Peres et al., 2009).

Atualmente, muitas fazendas situadas em bacias leiteiras, por várias razões, estão migrando da atividade leiteira para a pecuária de corte. Entretanto, tal migração vem sendo feita de forma muitas vezes não criteriosa ou sem assistência técnica; tal atitude pode promover perdas econômicas aos pecuaristas. Assim, neste estudo, objetivou-se analisar a viabilidade econômico-financeira e o risco financeiro de diferentes sistemas de cria de gado de corte, explorados em regiões de bacia leiteira.

\section{MATERIAL E MÉTODOS}

O trabalho consistiu em um estudo de múltiplos casos, seguindo o conjunto de etapas: formulação do problema; definição da unidade de caso; determinação no número de casos; elaboração do protocolo; coleta de dados; avaliação e análise dos dados e preparação do relatório, de acordo com a metodologia proposta por Gil (2002). Os sistemas de cria de gado de corte, doravante identificados como A, B e C, tiveram como critério de escolha serem sistemas que desenvolvessem atividade de cria de gado de corte e que tivessem confiabilidade na obtenção de registros dos dados de rebanho (índices zootécnicos), receitas e despesas. O horizonte de informações econômicas dos sistemas foi de 36 meses (janeiro de 2012 a dezembro de 2014). Cada sistema de criação foi caracterizado por meio de levantamento de dados realizados em visitas periódicas, utilizando-se um roteiro de questionamentos (questionário) previamente elaborados, o qual possibilitou maior organização e padronização das informações colhidas nas propriedades.

O sistema A, localizado no município de Mercês

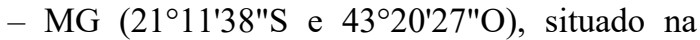
Zona da Mata de Minas Gerais, possuía 120,1 ha de área total de pastagens, a mão de obra era composta por um funcionário; eventualmente, havia contratação de mão de obra temporária para serviços diversos. A infraestrutura era composta por uma casa de colono, um curral de manejo para 80 animais, equipado com balança e tronco de contenção, um escritório e aproximadamente 9000 metros lineares de cercas. A base alimentar do rebanho era composta exclusivamente por pastagens, aliada à suplementação mineral, no período das águas e proteico-energética durante o período seco.

O sistema $\mathrm{B}$, localizado no município de Lorena

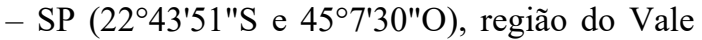
do Rio Paraíba, possuía uma área de 102,9 ha de pastagens. As benfeitorias eram formadas por uma casa de colono, um curral de manejo com 
capacidade para 100 animais equipado com tronco de contenção, balança e laboratório, um barracão de máquinas e equipamentos e 13000 metros lineares de cerca. As máquinas e os equipamentos correspondiam a um trator de $65 \mathrm{cv}$ de potência e implementos (duas roçadeiras, duas grades aradoras, um pulverizador, um subsolador, um distribuidor de fertilizantes). A mão de obra era composta por um funcionário que atuava na área de campo, responsável pelo manejo geral dos animais e pela manutenção de benfeitorias. $\mathrm{O}$ manejo nutricional adotado baseava-se em sistema de pasto com suplementação mineral, durante a época chuvosa, e fornecimento de suplemento proteicoenergético, durante a época seca.

O sistema C era desenvolvido em duas propriedades, localizadas no município de Valença, RJ (22 $14^{\prime} 45^{\prime \prime S}$ e $\left.43^{\circ} 42^{\prime} 00^{\prime \prime} \mathrm{O}\right)$, situado na região do médio Vale do Paraíba. As propriedades possuíam 516 e 484 hectares de pastagens. As benfeitorias eram compostas de três casas de colono, dois currais de manejo para 100 animais cada, um escritório, 15 cochos de sal mineral e, aproximadamente, 20 mil metros de cerca (divisas e divisões de pasto). As máquinas e os equipamentos eram compostos por dois tratores, um automóvel, dois troncos de contenção, duas balanças, um botijão de sêmen, dois aplicadores de sêmen e diversas ferramentas e implementos agrícolas. A mão de obra era composta por um administrador, um secretário, um tratorista e dois ajudantes gerais que atuavam na área de campo, responsáveis pelo manejo geral dos animais e pela manutenção das benfeitorias. $\mathrm{O}$ manejo nutricional adotado era baseado em sistema de pasto, com suplementação proteico-energética e mineral, nos períodos seco e chuvoso, respectivamente.

Todos os sistemas estudados tinham gerenciamento das informações zootécnicas (Tab. 1), baseado na coleta e na análise periódica de dados.

Tabela 1. Índices zootécnicos médios dos sistemas de cria de gado de corte (A, B e C), obtidos entre janeiro de 2012 e dezembro de 2014

\begin{tabular}{llll}
\hline \multirow{2}{*}{ Índice } & \multicolumn{3}{c}{ Sistema } \\
\cline { 2 - 4 } & $\mathrm{A}$ & $\mathrm{B}$ & $\mathrm{C}$ \\
\hline Intervalo de partos (meses) & 13,1 & 13,0 & 15,0 \\
Peso à desmama dos machos (kg) & 229,1 & 270,0 & 221,9 \\
Peso à desmama das fêmeas (kg) & 201,4 & 230,0 & 209,5 \\
Taxa de lotação (UA/ha) & 0,9 & 1,2 & 1,2 \\
Taxa de vacas em reprodução ${ }^{1}(\%)$ & 61,6 & 47,3 & 51,3 \\
Relação touro:vaca & $1: 33$ & $1: 30$ & $1: 20$ \\
Taxa de concepção (\%) & 54,0 & 60,0 & 49,0 \\
Taxa de natalidade (\%) & 78,1 & 83,0 & 71,8 \\
Taxa de desfrute (\%) & 20,8 & 23,6 & 28,3 \\
Taxa de mortalidade de animais de 0 a 1 ano (\%) & 0,0 & 2,5 & 7,1 \\
Taxa de mortalidade de animais > 1 ano (\%) & 0,0 & 0,0 & 3,2 \\
\hline
\end{tabular}

${ }^{1}$ Número de vacas em reprodução em relação ao número total do rebanho.

UA: unidade animal.

No início da realização das análises econômicofinanceiras (janeiro de 2012), o rebanho dos sistemas A, B e C era composto por 102 animais (73,1 UAs), 145 animais (96,8 UAs) e 1392 animais (1096,4 UAs), respectivamente (Tab. 2). Ao final do horizonte de coleta (dezembro de 2014), o rebanho dos sistemas A, B e C era composto de 151 animais (105,4 UAs), 207 animais (141UAs) e 1823 animais (1322,4 UAs), respectivamente (Tab. 2).
Em conjunto à caracterização dos sistemas, deu-se a coleta de dados econômicos tabulados em planilhas eletrônicas $\left(\mathrm{MS}-\mathrm{Excel}^{\circledR}\right)$. Para formação do fluxo de caixa, foram computadas as entradas e as saídas de cada sistema de criação. Foram admitidas como entradas as receitas advindas das vendas de animais e o valor do inventário dos bens imobilizados. As vendas de animais foram realizadas ao longo do período avaliado, e o valor do inventário foi estimado ao final deste. As saídas compreenderam o valor do 
inventário dos bens imobilizados no início do período $\mathrm{e}$ as despesas incorridas durante $\mathrm{o}$ período, tais como a compra de insumos, a manutenção de benfeitorias, máquinas e pastagens, as operações mecanizadas, o pagamento da mão de obra, os gastos com alimentação, medicamentos, taxas, impostos e outros itens considerados essenciais à manutenção dos sistemas de produção, dentro do horizonte estudado, conforme metodologia proposta por Netto (1999).

Tabela 2. Composição inicial (janeiro de 2012) e final (dezembro de 2014) dos rebanhos dos sistemas de cria de gado de corte (A, B e C)

\begin{tabular}{|c|c|c|c|c|c|c|c|c|c|c|c|c|}
\hline \multirow{3}{*}{ Categoria } & \multicolumn{6}{|c|}{ Inicial } & \multicolumn{6}{|c|}{ Final } \\
\hline & \multicolumn{2}{|c|}{ A } & \multicolumn{2}{|c|}{$\mathrm{B}$} & \multicolumn{2}{|c|}{$\mathrm{C}$} & \multicolumn{2}{|c|}{$\mathrm{A}$} & \multicolumn{2}{|c|}{$\mathrm{B}$} & \multicolumn{2}{|c|}{$\mathrm{C}$} \\
\hline & $\mathrm{N}^{\mathrm{O}}$ & UA & $\mathrm{N}^{\mathrm{O}}$ & UA & $\mathrm{N}^{\mathrm{O}}$ & UA & $\mathrm{N}^{\mathrm{O}}$ & UA & $\mathrm{N}^{0}$ & UA & $\mathrm{N}^{0}$ & UA \\
\hline Machos $<12$ meses & 7 & 2,1 & 25 & 7,5 & 186 & 55,8 & 19 & 5,7 & 39 & 11,7 & 187 & 56,1 \\
\hline $\begin{array}{l}\text { Machos } 12 \text { a } 24 \\
\text { meses }\end{array}$ & 15 & 9,0 & 0 & 0,0 & 110 & 66,0 & 0 & 0,0 & 0 & 0,0 & 348 & 208,8 \\
\hline Fêmeas $<12$ meses & 6 & 1,8 & 35 & 10,5 & 162 & 48,6 & 31 & 9,3 & 37 & 11,1 & 189 & 56,7 \\
\hline Fêmeas $12-24$ meses & 35 & 21,0 & 14 & 8,4 & 18 & 10,8 & 25 & 15,0 & 32 & 19,2 & 248 & 148,8 \\
\hline Matrizes & 34 & 34,0 & 66 & 66,0 & 890 & 890,0 & 69 & 69,0 & 95 & 95,0 & 792 & 792,0 \\
\hline Touros $<24$ meses & 0 & 0,0 & 2 & 1,6 & 0 & 0,0 & 3 & 2,4 & 0 & 0,0 & 12 & 9,6 \\
\hline $\begin{array}{l}\text { Touros } \\
\text { meses }\end{array}$ & 3 & 3,6 & 1 & 1,2 & 11 & 13,2 & 2 & 2,4 & 2 & 2,4 & 32 & 38,4 \\
\hline Equinos & 2 & 1,6 & 2 & 1,6 & 15 & 12,0 & 2 & 1,6 & 2 & 1,6 & 15 & 12,0 \\
\hline Total & 102 & 73,1 & 145 & 96,8 & 1.392 & $1.096,4$ & 151 & 105,4 & 207 & 141,0 & 1.823 & $1.322,4$ \\
\hline
\end{tabular}

UA: unidade animal.

O valor do inventário dos bens imobilizados foi calculado com base na quantidade de cada item (animais de produção e de trabalho, benfeitorias, máquinas, equipamentos e estoque) e dos valores informados pelos proprietários ou pelos preços de mercado cotados entre janeiro de 2012 e dezembro de 2014, respectivamente, para os bens imobilizados no início e no fim do período avaliado. Para o item valor de terra, seu preço foi corrigido de acordo com a taxa de inflação $(5,84$; 5,91 e $6,41 \%$ para os anos de 2012, 2013 e 2014, respectivamente), de acordo com Aguiar e Almeida (2002). O custo de depreciação dos bens, com vida útil superior a um ciclo produtivo, seguiu o método linear descrito por Lopes e Carvalho (2002). De posse do fluxo de caixa, foram realizadas as análises de viabilidade econômico-financeira. Foram adotados como indicadores econômicos de rentabilidade o valor presente líquido (VPL) e a taxa interna de retorno (TIR), seguindo-se a metodologia proposta por Contador (1988). Para o cálculo do VPL de cada sistema de produção, aplicaram-se taxas de desconto de 4, 6, 8 e $10 \%$ ao ano (a.a.) sobre o fluxo líquido mensal. Para a análise de sensibilidade, que indica o quanto do VPL varia em resposta à mudança do valor de um determinado item do fluxo de caixa mantendo-se os valores dos outros itens constantes, foi adotada uma variação de 10 pontos porcentuais para baixo nos valores dos itens de receitas (entradas) e de 10 pontos porcentuais para cima nos valores dos itens de despesas (saídas), segundo metodologia proposta por Weston e Ebrigham (2000). Posteriormente, identificaram-se os 10 itens que causaram maior variação no VPL, classificandoos por ordem decrescente.

A análise de risco foi realizada pelo método de Monte Carlo, conforme proposto por Noronha (1987). Por meio do programa MS-Excel ${ }^{\circledR}$, foi elaborada uma distribuição de probabilidade para cada uma das variáveis consideradas importantes, identificadas na análise de sensibilidade e inseridas na distribuição triangular (Bressan, 2002). Mediante a geração de números aleatórios, os valores foram obtidos para as variáveis em questão, resultando em vários fluxos de caixa e, consequentemente, vários indicadores de resultados (VPL) para cada sistema de produção. Com o objetivo de gerar uma distribuição de frequências do indicador para cada sistema, essa operação foi repetida 5.000 vezes, o que significa a geração de 5.000 possibilidades de ocorrência para o fluxo de caixa, com os preços variando entre o intervalo 


\section{Garcia et al.}

determinado. Essa análise permite aferir a probabilidade de sucesso ou insucesso de cada sistema de produção (Hertz, 1964).

\section{RESULTADOS E DISCUSSÕES}

Por apresentarem VPL maior que zero (R\$ $40.635,1 ; \mathrm{R} \$ 83.107,7$ e $\mathrm{R} \$ 17.945,3)$, os sistemas A, B e C foram viáveis financeiramente, quando submetidos a uma taxa de desconto de $6,0 \%$ a.a. Ou seja, pagaram seus custos de implantação e manutenção e ainda remuneraram o capital investido a uma taxa igual ou superior a 6\%. Entretanto, foram inviáveis quando a taxa de desconto foi acima de $8 \%$ a.a. (Tab. 3 ).

As taxas internas de retorno de 7,0; 7,3 e 6,1\% dos sistemas $\mathrm{A}, \mathrm{B}$ e $\mathrm{C}$, respectivamente, evidenciaram rentabilidade semelhante a outras alternativas de investimento. Essas taxas foram, por exemplo, ligeiramente superiores ou próximas à taxa média anual de rendimento da poupança do período estudado, de $6,3 \%$ a.a. (Caderneta..., 2015).

Tabela 3. Valor presente líquido (em R\$) considerando-se as taxas de desconto de 4, 6, 8 e $10 \%$ ao ano e a taxa interna de retorno anual (TIR) dos sistemas de cria de gado de corte (A, B e C) entre janeiro de 2012 e dezembro de 2014

\begin{tabular}{lccc}
\hline \multirow{2}{*}{ Taxa de desconto $(\%)$} & \multicolumn{3}{c}{ Sistemas de criação } \\
\cline { 2 - 4 } & $\mathrm{A}$ & $\mathrm{B}$ & $\mathrm{C}$ \\
\hline 4 & $\mathrm{R} \$ 129.652,4$ & $\mathrm{R} \$ 217.873,8$ & $\mathrm{R} \$ 431.615,9$ \\
6 & $\mathrm{R} \$ 40.635,1$ & $\mathrm{R} \$ 83.107,7$ & $\mathrm{R} \$ 17.945,3$ \\
8 & $-\mathrm{R} \$ 41.749,4$ & $-\mathrm{R} \$ 41.619,1$ & $-\mathrm{R} \$ 364.679,0$ \\
10 & $-\mathrm{R} \$ 118.103,6$ & $-\mathrm{R} \$ 157.218,9$ & $-\mathrm{R} \$ 719.088,2$ \\
\hline TIR & $7,0 \%$ & $7,3 \%$ & $6,1 \%$ \\
\hline
\end{tabular}

Outro ponto a ser considerado, em adicional aos indicadores econômicos de rentabilidade, é a taxa de valorização da terra que, de forma geral, foi acima da inflação no período avaliado. De acordo com o Instituto de Economia Agrícola do Estado de São Paulo (Valor..., 2015), as terras com pastagens cultivadas na região do Vale do Paraíba valorizaram, em média, 18,3\% a.a., entre os anos de 2012 e 2014, com acumulado de $55,0 \%$ no período avaliado (Valor..., 2015). A mesma tendência de valorização ocorreu para o estado de Minas Gerais, com taxa anual média de $21,0 \%$ e acumulado de $62,9 \%$, para o período de 2010 a 2013 (Índices..., 2015). Ao se descontar a inflação acumulada no mesmo período de $18,2 \%$ (Caderneta..., 2015), a valorização real do preço da terra foi de 36,8 e 44,7\% para os estados de São Paulo e Minas Gerais, respectivamente. Dessa forma, esses resultados de valorização das terras foram tão significativos quanto aqueles gerados pela atividade econômica dos sistemas A, B e C. Segundo Plata (2001), o imóvel rural, além de ser um ativo real e fator de produção de alimentos e insumos industriais, pode ser considerado um ativo de reserva de capital que muitas vezes conserva ou aumenta seu valor de um período para outro, principalmente nos anos de instabilidade econômica. Porém, como a terra é um capital imobilizado de baixa liquidez e de difícil reposição quando vendida, os sistemas de criação não devem contar com esse rendimento para cobrir possíveis déficits nos fluxos de caixas.

$\mathrm{Na}$ análise de sensibilidade (Tab. 4), foram identificados os impactos sobre o VPL dos sistemas (com taxa de desconto de 6\% a.a.) de eventuais flutuações nos preços dos itens do fluxo de caixa. Esses impactos foram estimados assumindo-se variações de $10 \%$ nos preços (elevação para itens de custo e queda para itens de entrada).

No sistema A, o retorno do investimento mostrou-se mais sensível ao preço de compra de terra, seguido pelos itens de investimento em cercas e matrizes (Tab. 4). O gasto com mão de obra representou o quarto item que mais onerou esse sistema. Os itens seguintes envolveram a compra e a venda de animais para o rebanho, tendo grande relevância o preço de negociação desses itens para esse sistema. O custo com pagamento de taxas, visitas de certificação e avaliação do rebanho foi item importante, devendo ser analisado de forma criteriosa quanto à sua viabilidade econômica, uma vez que houve despesas para sua manutenção. Entretanto, deve-se considerar que animais registrados e 
certificados tendem a ter maior valorização na comercialização, o que pode compensar o investimento prévio neles, além de garantir qualidade genética para os compradores e servirem para reposição no próprio criatório.

$\mathrm{O}$ investimento em terra foi o item que mais impactou negativamente o sistema B. Em seguida, ficaram ranqueados os itens investimentos em matrizes e em cercas. A rentabilidade do sistema ainda se mostrou sensível aos preços de venda de bezerros e de vacas de descarte e à compra de bezerras, de novilhas e de um trator.

A rentabilidade do sistema $\mathrm{C}$ também foi mais sensível ao valor de compra da terra, seguida pelos itens de investimento em matrizes e novilhas, venda de vacas de descarte, venda de boi gordo, de animais desmamados, ressaltandose a importância das negociações dos animais (compra e venda). Os gastos com mão de obra representaram o quarto item que mais onerou esse sistema. Somado a estes, os gastos com aluguel de pastagens também constituíram um item de destaque para o sistema $\mathrm{C}$.

Tabela 4. Análise de sensibilidade (mudança do VPL) dos sistemas de cria de gado de corte (A, B e C) entre janeiro de 2012 e dezembro de 2014

\begin{tabular}{|c|c|c|}
\hline Sistema & Itens do fluxo de caixa & Variação do VPL \\
\hline \multirow{10}{*}{ A } & Investimento em terra & - $\mathrm{R} \$ 108.171,0$ \\
\hline & Investimento em cerca & - $\mathrm{R} \$ 8.504,2$ \\
\hline & Investimento em matrizes & - $\mathrm{R} \$ 6.800,0$ \\
\hline & Gastos com mão de obra permanente & - $\mathrm{R} \$ 4.096,6$ \\
\hline & Venda de bezerros $(<1$ ano $)$ & - $\mathrm{R} \$ 3.513,8$ \\
\hline & Investimento em novilhas & - R\$ 3.465,0 \\
\hline & Venda de touro jovem $(<24$ meses $)$ & $-\mathrm{R} \$ 2.355,4$ \\
\hline & Venda de bezerras $(<1$ ano) & - R\$2.090,8 \\
\hline & Investimento em touro reprodutor & $-\mathrm{R} \$ 1.522,2$ \\
\hline & Gastos com associação de criadores & - R\$916,4 \\
\hline \multirow{10}{*}{ B } & Investimento em terra & - $\mathrm{R} \$ 154.350,0$ \\
\hline & Investimento em matrizes & - R\$ $18.480,0$ \\
\hline & Investimento em cerca & - R\$ $11.050,0$ \\
\hline & Venda de bezerros $(<$ ano $)$ & - $\mathrm{R} \$ 7.412,2$ \\
\hline & Venda de vacas descarte & - $\mathrm{R} \$ 4.731,9$ \\
\hline & Gastos com mão de obra permanente & - $\mathrm{R} \$ 4.382,1$ \\
\hline & Investimento em bezerras ( $<1$ ano) & - $\mathrm{R} \$ 3.150,0$ \\
\hline & Investimento em novilhas (de 1 a 2 anos) & - $\mathrm{R} \$ 1.820,0$ \\
\hline & Investimento em trator & - $\mathrm{R} \$ 1.500,0$ \\
\hline & Gastos com associação de criadores & - R\$ $1.395,0$ \\
\hline \multirow{10}{*}{$\mathrm{C}$} & Investimento em terra & - $\mathrm{R} \$ 414.606,5$ \\
\hline & Investimento em matrizes & - $\mathrm{R} \$ 152.628,7$ \\
\hline & Venda de vacas descarte & - $\mathrm{R} \$ 47.069,2$ \\
\hline & Gastos com mão de obra permanente & - $\mathrm{R} \$ 34.821,6$ \\
\hline & Venda de boi gordo & - R\$33.464,6 \\
\hline & Venda de bezerras $(<1$ ano $)$ & - R\$27.266,3 \\
\hline & Venda de bezerros ( $<1$ ano) & - R\$ 20.947,0 \\
\hline & Investimento em cercas & - R\$16.985,6 \\
\hline & Investimento em novilhas & - R\$ $16.959,8$ \\
\hline & Gastos com aluguel de pastagens & - R\$ $15.810,4$ \\
\hline
\end{tabular}

VPL: valor presente líquido.

Portanto, de forma geral, os itens que mais exerceram impacto negativo sobre o VPL foram os investimentos em terra, na compra de matrizes para a composição do rebanho e a construção de cercas. Esses resultados corroboram a afirmativa de Lazzarini Neto (2000) quanto à menor rentabilidade econômica da atividade de cria em relação à recria e à terminação. Isso se deve ao 


\section{Garcia et al.}

grande capital imobilizado em matrizes, touros, novilhas e na própria terra. A rentabilidade dos sistemas também foi muito sensível ao custo com a mão de obra, ressaltando a importância em otimizar esse fator de produção dentro de cada sistema, seja pelo aumento na escala de produção, seja pela capacitação para outras atividades a serem realizadas, objetivando sempre a redução do custo por unidade de produto.

Ao não se considerarem os custos com investimentos e mão de obra, os itens venda de animais desmamados, novilhas, boi gordo, tourinhos e vacas de descarte foram aqueles que tiveram grande impacto nos resultados. $\mathrm{O}$ item venda de vaca de descarte também teve relevância nos resultados dos sistemas $\mathrm{B}$ e C, fato justificado por estes não terem o rebanho de matrizes estabilizado. Dias e Osaki (2010) postularam que, para os sistemas de cria, o bezerro é a principal fonte de renda, e a receita

Sistema A

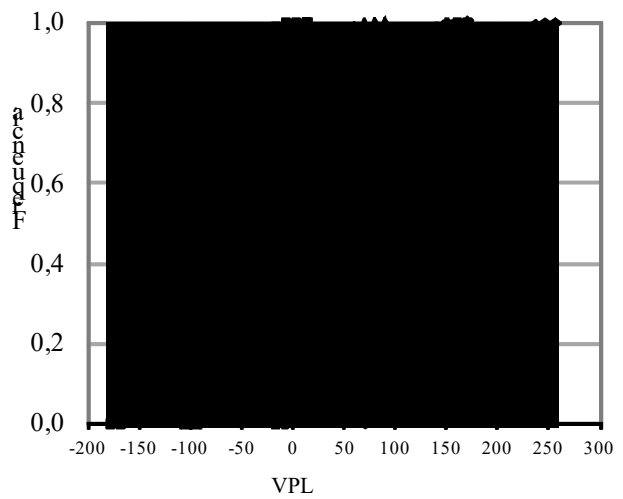

obtida com as demais categorias é complementar; opinião não sustentada pelos resultados obtidos neste estudo.

Os riscos inerentes a cada sistema, associados a eventuais flutuações nos preços dos itens de maior participação nos resultados, foram avaliados e identificados pela análise de sensibilidade. Mediante a simulação dos preços pelo método de Monte Carlo, foram estimadas as probabilidade de os sistemas tornarem-se inviáveis; ou seja, assumirem valores negativos para o VPL, a diferentes taxas de desconto.

Na Fig. 1, encontra-se representada a distribuição acumulada de probabilidade dos VPLs obtidos para cada sistema e a taxa de desconto utilizada. $\mathrm{Na}$ Tab. 5, são resumidas as probabilidades de obtenção de VPL negativo (valor da ordenada das figuras no ponto em que seu eixo é cruzado pela curva da distribuição).

Sistema B

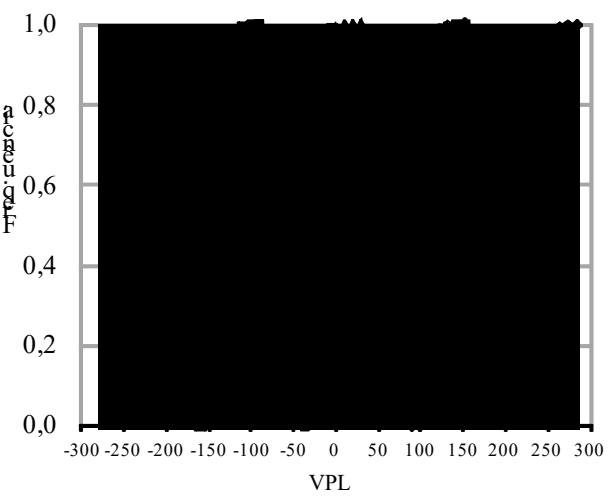

Sistema C

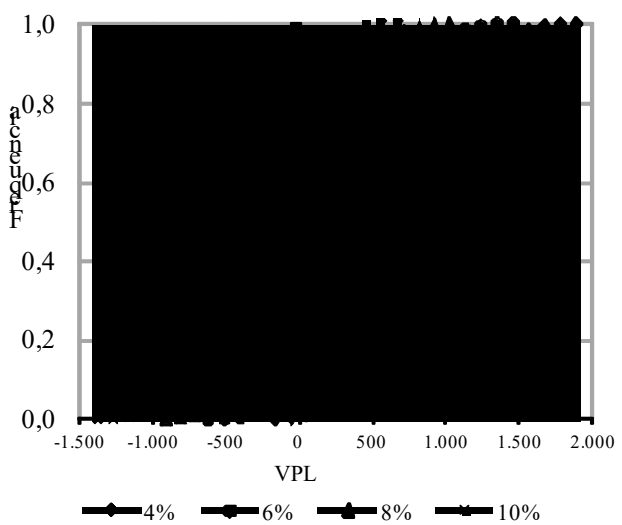

Figura 1. Distribuição das frequências acumuladas e seus respectivos VPLs simulados, quando aplicadas taxas de descontos de 4, 6, 8 e 10\% ao ano, nos sistemas de cria de gado de corte (A, B e C), entre janeiro de 2012 e dezembro de 2014. 
Tabela 5. Risco financeiro da atividade (\%) quando submetida às taxas de desconto de 4, 6, 8 e $10 \%$ ao ano para os sistemas de cria de gado de corte (A, B e C), entre janeiro de 2012 e dezembro de 2014

\begin{tabular}{c|ccc}
\hline \multirow{2}{*}{ Taxa de desconto (\% a.a.) } & \multicolumn{3}{c}{ Sistema de criação } \\
\cline { 2 - 4 } & $\mathrm{A}$ & $\mathrm{B}$ & $\mathrm{C}$ \\
\hline 4 & 0,00 & 0,00 & 0,53 \\
6 & 0,79 & 7,92 & 10,43 \\
8 & 58,67 & 99,03 & 36,66 \\
10 & 99,84 & 100,00 & 76,17 \\
\hline
\end{tabular}

A uma taxa de desconto de $4 \%$ a.a., foi praticamente nula a probabilidade de que os sistemas se tornassem inviáveis (Tab. 5). À taxa de desconto de $6 \%$ a.a., a probabilidade de esses sistemas tornarem-se inviáveis ainda foi baixa, porém mais elevada para os sistemas B e C (Tab. 5). Considerando-se que essa taxa foi próxima ao rendimento médio com a caderneta de poupança $(6,3 \%$ a.a.), entende-se que foi baixa a probabilidade de que os sistemas não atingissem, pelo menos, a rentabilidade dessa aplicação. Constata-se, por outro lado, que foi alta a probabilidade de que esses sistemas não alcançassem as demais taxas de retorno avaliadas (Tab. 5). Simões et al. (2006), ao analisarem três sistemas de produção pecuária (cria, recria e engorda) para a região do Pantanal Sul-MatoGrossense, revelaram que, entre os sistemas, a cria teve o menor resultado econômico; no entanto, esse sistema foi o único a não ter possibilidade de lucro negativo, ou seja, risco $0,0 \%$. De acordo com os autores, esses resultados se deveram à estrutura de custo do sistema de cria, em que a maior parte foi associada ao capital estável (instalações, matrizes e touros, máquinas etc.); dessa forma, o sistema de cria encontra-se mais protegido das flutuações de preço do mercado que sabidamente influenciam os custos de produção.

Neste estudo, deve-se ainda considerar que, na análise probabilística do risco financeiro, não se consideraram aqueles oriundos de possíveis mudanças climáticas que pudessem influenciar na produtividade dos sistemas e, consequentemente, alterar seus índices zootécnicos e financeiros, fato que poderia aumentar os riscos desses sistemas.

\section{CONCLUSÕES}

Os sistemas de cria de gado de corte são viáveis economicamente a uma taxa de desconto de $6 \%$ a.a. As taxas de retorno obtidas com tais sistemas de cria são atrativas para investimentos. Os investimentos em terra e em matrizes são os itens mais sensíveis do fluxo de caixa, quando submetidos a uma taxa de desconto de $6 \%$ a.a. Os sistemas de cria possuem baixo risco financeiro, tornando-se opções de investimentos atrativas, quando submetidos à taxa de rendimento real da caderneta de poupança.

\section{AGRADECIMENTOS}

À Fundação Carlos Chagas Filho de Amparo à Pesquisa do Estado do Rio de Janeiro (Faperj), pela concessão do financiamento do estudo.

\section{REFERÊNCIAS}

AGUIAR, A.P.A.; ALMEIDA, B.H.P.J.F. Planejamento e administração da produção de leite e carne no Brasil. Uberaba, MG: FAZU, 2002. 92p.

BARCELLOS, J.O.J. A importância da cria na pecuária de corte. In: BARCELLOS, J.O.J.; OLIVEIRA, T.E.; MARQUES, P.R. et al. (Eds.). Bovinocultura de corte: cadeia produtiva \& sistemas de produção. Guaíba, Rio Grande do Sul: Agrolivros, 2011. p.61-64.

BRESSAN, G. Modelagem e simulação de sistemas computacionais: abordagem sistemática de modelagem e análise de desempenho de sistemas. São Paulo: Larc-PCS/Epusp, 2002, $12 \mathrm{p}$.

CADERNETA de poupança. Índices mensais. São Paulo: Base de dados do Portal [s.1.]: ABECIP, 2015. Disponível em: $<$ http://www.portalbrasil.net/poupanca_mensal.h tm>. Acessado em: 11 maio 2015.

CONTADOR, C.R. Avaliação social de projetos. 2.ed. São Paulo: Atlas, 1988. 316p. 


\section{Garcia et al.}

DIAS, L.F.; OZAKI, P.M. Caracterização da atividade pecuária de cria nos municípios de Goiás: Niquelândia, Rio Verde, Porangatu nos anos de 2003-2008. São Paulo: CEPEA/ESALQ, 2010. Disponível em: <http://www.sober.org.br/ palestra/15/1020.pdf $>$. Acessado em: 05 out. 2014.

GIL, A.C. Como elaborar projetos de pesquisa. 4.ed. São Paulo: Atlas, 2002. 255p.

HERTZ, O.B. Risk analysis in capital investment. Harv. Bus. Rev., v.42, p.95-106, 1964.

ÍNDICES de preços de terras. Belo Horizonte: Faemg, 2015. Disponível em: $<$ http://www.faemg.org.br/Conteudo.aspx?C ode $=69 \&$ Portal $=2 \&$ ParentCode $=67 \&$ ParentPath $=$ None $\&$ ContentVersion $=\mathrm{R}>$. Acessado em: 20 jun. 2015 .

LAZZARINI NETO, S. Cria e recria. 3.ed. Viçosa: Aprenda Fácil, 2000. v.2, 120p. (Coleção Lucrando com a pecuária).

LOPES, M.A.; CARVALHO, F.M. Custo de produção de gado de corte. Lavras: UFLA, 2002. 47p. (Boletim técnico, n.47)

JOSÉ NETTO, E. Olho no caixa: como desenvolver sua visão sobre a administração financeira. São Paulo: Nobel, 1999. 144p.
NORONHA, J.F. Projetos agropecuários: administração financeira, orçamento e viabilidade econômica. 2.ed. São Paulo: Atlas, 1987. 269p.

PERES, A.A.C.; VASQUEZ, H.M.; SOUZA, P.M. et al. Análise financeira de sistemas de produção de leite em pastagens: indicadores econômicos e análise de sensibilidade. Rev. Bras. Zootec., v.38, p.2072-2078, 2009.

PLATA, L.E.A. Mercado de terra no Brasil: gênese, determinação de seus preços e políticas. 2001. 215f. Tese (Doutorado em Economia) Universidade Estadual de Campinas, Campinas, SP.

SIMÕES, A.R.P.; MOURA, A.D.; ROCHA, D.T. Avaliação econômica comparativa de sistemas de produção de gado de corte sob condições de risco no Mato Grosso do Sul. Rev. Econ. Agronegócio, v.5, p.51-72, 2006.

VALOR de terra nua. São Paulo: IEA, 2015. Disponível em: $<$ http://www.iea.sp.gov.br/out/bancodedados.htm 1>. Acessado em: 16 jun. 2015.

WESTON, J.F.; EBRIGHAM, E.F. Fundamentos da administração financeira. 10.ed. São Paulo: Pearson Makron Brooks, 2000. 1030p. 